\title{
The complexities of interdisciplinarity: Integrating two different perspectives on interdisciplinary research and education
}

\author{
ANGUS MCMURTRY \\ University of Ottawa (Canada)
}

\begin{abstract}
The aim of this article is to open a conversation between the complexity \& education community and the field of interdisciplinarity (as well as its close relative, interprofessionalism). It starts by describing two very different streams of thought in the literature on interdisciplinary research and education: One that focuses on the socio-cultural dynamics among disciplinary 'knowers' and one that emphasizes the complexity of the phenomena studied by these disciplinary knowers. Next, the author argues that recent epistemological thinking associated with the complexity $\mathcal{E}$ education community can help to integrate these streams of thought—offering a way for interdisciplinary inquiry to respect both the complexity of knowers and the complexity of the known.
\end{abstract}

\section{Introduction}

Interdisciplinarity and interprofessionalism are topics of growing concern in higher education institutions. Faced with multifaceted problems like climate change and poverty, many researchers and educators have explicitly adopted interdisciplinary outlooks. In healthcare professional schools across the developed world, practitioners are being trained for work in interprofessional teams-teams that policymakers hope will be more effective in providing care for complex health issues like diabetes. ${ }^{1}$ Not

\footnotetext{
${ }^{1}$ In Canada, for example, the establishment of interdisciplinary teams is one of the five pillars of Health Canada's current $\$ 800$ million push to reform primary health care (Health Canada, 2005).
} 
surprisingly, the conceptual frameworks and curricula used in interdisciplinary and interprofessional programs in post-secondary institutions are only just starting to emerge. A variety of different-sometimes even conflicting - theoretical viewpoints are taking root. The present is therefore a good time to critically examine the literature around which these conceptual frameworks and curricula are coalescing.

This article will begin by taking up a previous discussion in Complicity concerning complexivist perspectives on interdisciplinarity in education and use it as a starting point to explore a dichotomy in the interdisciplinary and interprofessional literature. This literature presents two very different ways of thinking about disciplinary knowledge and the challenges of integration. One perspective conceives these issues in terms of irreducible differences in 'the real world,' among the sorts of phenomena studied. The other perspective explains them primarily in terms of socio-cultural dynamics within and among the 'knowers' (i.e. disciplinary or professional groups) doing the studying. Unfortunately, interdisciplinary thinkers generally tend to adopt only one of these perspectives and neglect the other. There is thus a need for an integration of perspectives-one that acknowledges both the complexity of phenomena and the complexity of knowers - in order that a more robust framework for interdisciplinary education and research might emerge.

In the final section, I turn to epistemological ideas developed within the complexity \& education community and by a number of theorists who have inspired this community. I will argue that these complexivist and complexity-compatible ideas about learning and knowing can provide a way to integrate, without conflating, the two perspectives-thus providing a more open and productive space for interdisciplinary and interprofessional education and research. The goal of this paper is therefore not to introduce entirely new ideas to the complexity \& education community; rather, it is to bring this community into a productive conversation with a relatively new and growing field that is facing similar epistemological challenges.

\section{Definitions}

I will adhere in this paper to a widely accepted definition of interdisciplinarity. I will define it as not only drawing upon two or more disciplinary perspectives in order to better understand or address a certain issue or problem-mere multidisciplinarity-but also attempting to integrate insights from these perspectives in a way that may lead to the emergence of transcendent perspectives (Klein \& Newell, 1998; Augsburg, 2006; Repko, 2008).

The related term transdisciplinarity is more difficult to pin down, as it is used in a variety of ways in a number of different contexts. ${ }^{2}$ The authors I will refer to in the

\footnotetext{
${ }^{2}$ For instance, some authors (usually in European circles) use it to refer either to a principle for a unity of knowledge beyond disciplines or to interdisciplinary approaches to 'real world' problems involving multiple stakeholders, which require not only intellectual integration but also the political negotiation of conflicting interests (Newell, Association for Integrative Studies (AIS)
} 
current paper, however, define it in much the same way as interdisciplinarity is defined above. One important difference, though, is that they typically place more emphasis on transcendent perspectives and reserve the term interdisciplinarity for the more modest task of drawing upon and integrating disciplinary insights (see, for example, Stokols et al., 2008; Phelps \& Davis, 2005).

The term interprofessionalism parallels interdisciplinarity, in the sense that interprofessional activities seek to draw upon and integrate diverse professional perspectives. However, the focus of interprofessionalism is more practical: Better collaboration among professional practitioners (e.g. in health care) rather than the development of new domains of knowledge (D'Amour \& Onadasan, 2005). As I implied above, however, many of the same theoretical issues are at stake and so I will discuss several contributions from the interprofessional literature.

\section{Taking Up a Previous Discussion}

The topic of interdisciplinarity is not entirely new to Complicity. In the lead editorial of the 2005 issue of Complicity: An International Journal of Complexity and Education, Phelps and Davis suggest that education ought to be understood as a transphenomenal enterprise, since even

something as "simple" as a personal understanding of a physical event [is] likely rooted in biological structure (genetic predisposition), framed by bodily activity (personal experience), elaborated within social interactions (symbolic tools), enabled by cultural tools (societal usages), and part of an ever-unfolding conversation of humans and the biosphere. (p. 2)

Because education involves so many levels of interconnected phenomena, Phelps and Davis (2005) write, researchers studying these phenomena ought to adopt a transdisciplinary ${ }^{3}$ attitude. To understand personal learning, for example, one might draw productively upon the insights of neurology, psychology, sociology, anthropology and evolutionary discourses.

Furthermore, they argue, complexity thinking offers a means to conceptually bridge such seemingly incompatible disciplinary perspectives. It does so by emphasizing that different sorts or levels of phenomena embody emergent qualities that transcend their parts and reflect their unique histories; they therefore need to be studied "at the levels of their emergence" (p. 2). Complexity can thus act as sort of "interdiscourse," negotiating the relationships between disciplinary discourses-while never reducing or conflating them (p. 3).

Phelps and Davis' assertion concerning inter- or transdisciplinarity can be interpreted in two different ways. First, most obviously, it applies to what is 'known';

Listserve communication, April 13, 2008; Wikipedia, 2008, http://en.wikipedia.org/wiki/Transdisciplinarity)

${ }^{3}$ Although Phelps and Davis use of the term "transdisciplinary" rather than "interdisciplinary", their definition of this term is compatible with the broad definition of interdisciplinary given at the beginning of this article. 
that is, one must attend to the complexity of the phenomenon one is studying and its interrelationships with other phenomena. Secondly-more subtly and reflexively-their complexivist understanding of learning can be applied to the 'knowers' doing the studying; that is, researchers (disciplinary and interdisciplinary) must acknowledge that their knowledge is a construction necessarily shaped by the their embodied, biological, social, cultural and political history. In education, for instance, this means that both the student learning we study and our own research may be understood as complex processes interlinked with many other sorts of complex phenomena.

In the past 10 years, theorists based in a variety of fields have provided sophisticated accounts of interdisciplinary research and interprofessional practice as complex processes that require careful negotiation of often incommensurable perspectives. Some of these accounts are beginning to define the curriculum in interdisciplinary and interprofessional programs. For instance, the writings of Newell (2001a; 2001b) and Klein (2004; 1996; 1986), which are described below, are considered foundational within many US graduate and undergraduate interdisciplinary programs (AIS Connected Publications, 2010).

What is most interesting about these accounts, however, is that they are divided into two parallel but quite different streams of thought-roughly equivalent to the two interpretations above-with little productive intercourse between them. One stream focuses the irreducibility or complexity of the phenomena under study, while the other emphasizes socio-cultural dynamics among the 'knowers' doing the studying. In the following two sections, I provide an overview and several illustrations of each strand, drawing upon interdisciplinary and interprofessional literature in fields as diverse as health, criminology and the humanities.

\section{Focusing on the complexity of phenomena}

One major stream of thinking is often associated with thinkers in the physical and health sciences, as well as some social sciences. It frames disciplinarity and interdisciplinary integration primarily in terms of the various phenomena (rocks, cells, organisms, economies, cultures, and so on) that researchers study-specifically the irreducibility or incommensurability among different sorts of phenomena and consequent need for both disciplinary diversity and some sort of integrative process.

Within the theoretical literature on interdisciplinarity, this phenomena-focused perspective is perhaps best articulated by well-known interdisciplinarian William Newell (2001a). Like many contemporary thinkers associated with this perspective, Newell explicitly invokes complexity science, arguing that it offers "a comprehensive and long overdue rationale" for interdisciplinary study as well as practical guidance for the process of disciplinary integration (p. 6).

Newell (2001a) writes that each discipline focuses on one facet of reality, that is, a set of variables observable from its perspective that are closely and linearly related. For instance, chemistry focuses on the structure and interaction of matter, especially at the atomic and molecular levels, while sociology studies human social behaviour and 
society's institutions and organization. However, most real world problems or issues are multifaceted, incorporating multiple sets of variables that interact in non-linear ways. Newell himself uses the problem of acid rain, which emerges through the interaction of chemical reactions, biological processes, hydrological cycles, global economic trends, and cultural and political developments (p. 16). Such multifaceted phenomena can be seen, he writes, as complex systems and their relatively simple, linearly-related facets can be seen as component parts (p. 3). Interdisciplinary research-whether conducted by professional academics or university students-is therefore about integrating disciplinary insights concerning various components in order to better identify and make sense of a particular complex system (Newell, 2001a, p. 16). The practical steps Newell offers for carrying out such integration include (among other things) identifying a problem or topic, developing and gathering disciplinary insights, articulating assumptions, conflicts and possible common grounds, and finally producing (and perhaps testing) a new, emergent understanding or model (2001a, p. 15)

Newell's (2001a) linking of complexity with interdisciplinarity differs in several respects from the account offered above by Phelps and Davis (2005). Obviously, he is concerned with all areas of interdisciplinary research, rather than just education. Second, Newell's (2001a) theorizing is focused on the phenomena studied by disciplinarians and pays relatively little attention to disciplinary knowers themselves. Phelps and Davis (2005) are not directly concerned with disciplinary knowers. But as noted above, the phenomenon they focus on is learning or knowing, and so their analysis could be reflexively extended to the researchers doing the studying as well.

Third, while both Newell (2001a) and Phelps and Davis (2005) see complexity science as offering a framework for interdisciplinarity, they differ in how they map it onto the phenomena studied by disciplines. Newell (2001a) sees individual disciplines as concerned with relatively simple components ("variables that are closely and linearly related"); as we saw above in the example concerning acid rain, complex systems that incorporate multiple components are the proper domain of interdisciplinary enquiry. By contrast, Phelps and Davis (2005) view even individual disciplines as being concerned with complex systems - each one focused on a differing sort or level of complex system. These differing systems or levels are depicted as being organized in a multilevel or 'nested' ecological structure. For instance, individuals can be seen as nesting within larger complex systems such as social groups, cultures and ecosystems. The job of interdisciplinary (or transdisciplinarity) research is, therefore, to reach across these various complex systems and negotiate among the disciplinary perspectives associated with them.

Significantly, this latter ecological, multilevel understanding of phenomena and disciplinarity has begun to manifest itself in several other fields of inquiry-including healthcare and criminology. In healthcare literature, it typically takes the form of holistic, multi-levelled, 'cells-to-society' conceptions of health and healthcare. That is, the health of an individual human being is understood as depending crucially on-and nesting ecologically among-a number of living systems, ranging from the cells and organs within his or her own body, to the social, cultural and ecological collectives in 
which he or she participates. ${ }^{4}$ Effective diagnosis and treatment of a patient with an ulcer, for example, may require not only knowledge of the physiological issues at the cellular and organ levels, but also an understanding of what is going on the personal, social and economic levels (for example, possible addiction to alcohol, troubled relationships with friends and family, and workplace cutbacks). Again, complexity science is used by many of these thinkers as a framework for relating-without reducing or conflating-knowledge concerned with these differing sorts of living systems (see, for example, Bell et al., 2002; the Plexus Institute, http://plexusinstitute.org).

A similar approach is becoming common in criminology. Barak (1998),for instance, argues that current analyses of crime are fragmented and isolated; what is needed are accounts that integrate the dynamic and interactive processes occurring at multiple interpersonal, institutional and structural levels. Robinson and Beaver (2008) seek to transcend the disciplinary myopia that characterizes much criminological theory, taking a 'cells-to-society' approach that draws upon disciplines as diverse as biology, sociology, psychology, anthropology and economics. Henry (2009) has makes use of these and other theorists to articulate an interdisciplinary understanding of school violence, one that acknowledges the complex, multilevel processes that underlie seemingly isolated events. In concrete terms, this means not only recognizing but also integrating insights concerning everything from the neurological correlates of persistent behavioural problems, to family breakdown or school failure, to poverty, bullying, racism and institutionalized discrimination (Henry, 2009, p. 1249).

Although many similar examples of this approach exist, the above is sufficient to illustrate the main point of this section: That there is a well developed stream of thought in the interdisciplinary and interprofessional literature which seeks to explain disciplinary differences and interdisciplinary integration based on the irreducibility or incommensurability of the phenomena under study. Many of these accounts are either compatible with, or explicitly invoke, complexity science.

There is, however, something lacking in this stream of thought, something that becomes clear as one surveys other interdisciplinary literature. What is lacking is a reflexive acknowledgement of disciplinary (and interdisciplinary) 'knowers' themselves. The influence of history, politics, economics and other socio-cultural factors on their knowledge is absent from the picture. This realization takes us to the other major perspective on disciplinary knowledge and interdisciplinary integration.

\section{Focusing on socio-cultural dynamics}

The other stream of thought is typically linked to thinkers in the humanities, sociology, social psychology and some healthcare areas. It explains disciplinary boundaries and

${ }^{4}$ See, for example, the American Journal of Preventive Medicine's (2008) supplement on "The Science of Team Science: Assessing the Value of Transdisciplinary Research", especially articles by Hiatt \& Breen (2008), Mabry et al. (2008), and Leischow et al. (2008), which take either explicitly complexivist or complexity-compatible socio-ecological or systems-oriented approaches to health and healthcare. 
interdisciplinarity in terms of the socio-cultural dynamics among the 'knowers' doing the studying, concentrating on issues such as class, gender, history, economic interests and professional socialization.

Julie Thompson Klein (1986) is probably the best known interdisciplinary theorist internationally and, as a result, has had a major influence on interdisciplinary research and education. She explains disciplinarity and interdisciplinarity almost entirely in terms of the dynamic tensions that arise within and among disciplines as they co-evolve, often splitting, joining or giving birth to new "hybrid" disciplines such as "immunopharmacology" (p. 86). Supporting her ideas with innumerable examples from interdisciplinary research in a wide variety of fields, she demonstrates how issues of discourse, status, history and context continually shape both disciplinary and interdisciplinary knowers and knowledge. Her "socio-linguistic" approach for integrating —or at least managing-complex, interdisciplinary problems puts a much greater emphasis on power than Newell's approach (Klein, 2001, pp. 52-53). For example, she points out that the "common ground" identified by interdisciplinary research groups may hinge much more on "the political economy of status hierarchies" among disciplinary participants than on an intellectual understanding of a system's behaviour (Klein, 2001, pp. 52).

What is most striking about Klein's sophisticated accounts is that she makes virtually no reference to the world or phenomena themselves. That is, the world seems not to have any sort of structure or integrity beyond how it is construed by human beings. "Life," she writes, "is a neutral assortment of phenomena that are ordered through human thought and action" (Klein, 1996, p. 12).

This focus on socio-cultural dynamics is also manifested in literature on professionalism and interprofessionalism. In The System of Professions: An Essay on the Division of Expert Labor, sociologist Andrew Abbott (1988) argues that the modern professions constitute an interdependent system. To understand them, one should look less at specific professions in isolation and more at the dynamic interactions that go on among them. His characterization of professionalism is multileveled and ecological: One must attend to 1) competition and cooperation within professions, for example, between sub-specialties, 2) competition and cooperation among professions, and 3) the influence of external forces like changes in laws and the marketplace (p. 143). The power of a profession, in Abbott's account, is equated with its ability to defend and expand its jurisdiction (i.e. turf) in the face of various systemic forces (p. 136).

In the context of interprofessional healthcare teams, Beattie (1995) uses the anthropological metaphor of tribes to analyze health profession boundaries, arguing that each profession has its own explanatory framework or 'cultural bias' (p. 20). Each of these professional frameworks finds its justification through differing sets of interests, relationships, and social and institutional values (p. 20). In a similar vein, Hall (2005) describes how health professions-through education, socialization and political tensions-develop different 'cognitive maps' and often use their expertise as an ideological tool for power and control. For instance, one profession may seek to heighten the contrast between itself and other rival professions in order to expand its authority. 
Given this focus on socio-cultural factors, it is not surprising that Hall's (2005) suggestions for fostering effective interprofessional teamwork center on issues such as communication (team members making their cognitive maps and values clear to one another) and power (fostering equal status among team members) (pp. 190-192). Significantly, Neither Beattie nor Hall explicitly addresses the possibility that professional differences and interprofessional teamwork may also crucially involve something other than socio-cultural dynamics-say, incommensurabilities among the differing sorts of phenomena with which health professionals engage (cells, organs, whole person and so on).

From the illustrations provided above, then, it should be apparent that literature oriented towards the socio-cultural dynamics of disciplinary and interdisciplinary 'knowers' (as well as professional and interprofessional 'knowers') has its own rich tradition of thought. As with the previous stream of thought, however, one gets the sense that something is missing. A persuasive story concerning disciplinary knowledge and interdisciplinary integration is offered strictly within the bounds of human knowing and culture; the "more-than-human" (Abram, 1996) world that many disciplinarians and interdisciplinarians (e.g. those working in the natural and health sciences) arguably engage with is little more than an inert and neutral background.

\section{Two stories}

The preceding sections show that there are a two important, but quite different, stories being told about the nature of disciplinarity and interdisciplinarity. One story emphasizes the complexity of the phenomena 'known,' engaging it as something 'real,' with an objective existence and structure that is not simply a function of knowers' constructions. The other story focuses on the socio-cultural dynamics within and among the various 'knowers.' Unfortunately, these two perspectives largely ignore one another's existence. That is, thinkers in each strand generally fail to engage deeply with the story described by the other.

A few of the more sophisticated interdisciplinary and interprofessional thinkers do offer some acknowledgement to the other side. Among those who emphasize the complexity of phenomena, Newell admits a role for socio-cultural factors in shaping knowledge; he is certainly no naïve realist. But he only really brings up this point in reply to socio-cultural-oriented critics who deny any sort of interface between human knowledge and reality:

I am increasingly frustrated by either/or ontological thinking that presumes we either have full, direct access to reality or no knowledge of reality at all. As interdisciplinarians, we need to get past such dichotomies. (Newell, 2001b, p. 141)

Unfortunately, he appears not to pursue these ideas, and what might lie beyond this dichotomy, any further.

Among those who concentrate on knowers and socio-cultural dynamics, Klein (2004), in a more recent paper, mentions reality as a "nexus of interrelated phenomena that are not reducible to a single dimension" (p. 4). The structure of the more-than- 
human world, however, plays very little role in her actual theorizing. Abbott (1988) goes into a little more detail. He recognizes that the human problems that structure professional tasks, identifications and boundaries may have at least some "objective" aspects. These objective aspects range from the technological and organizational-which seem merely to be relatively slow changing human creations-to "natural objects and facts" (p. 39). Abbott treats all three as "fixed" in comparison to faster moving cultural developments (pp. 38-39). However, his discussion of such objective factors is quite brief and his depiction of the more-than-human world is homogenous and simplistic in comparison to the phenomena-focused, complexivist thinkers described above.

Although not concerned with interdisciplinarity or interprofessionalism per se, theorists classified as sociologists of scientific knowledge (SSK) have extensively debated the exact nature of the relationship between scientists and the world they study. Even among SSK theorists, however, one finds the tendency to neglect the complexities of either knowers or the phenomena known. One group, often described as being part of the 'weak program,' view socio-cultural factors merely as providing a context for scientific discovery or as providing explanation for erroneous beliefs; such factors are deemed to be irrelevant for accurate scientific belief, which "answer [only] to nature and reason, not society" (Bloor, 1999, p 82). Those aligned with the 'strong program,' on the other hand, stress the crucial role played by socio-cultural factors in all scientific beliefs (Bloor, 1999, p 88). The latter have been criticized, however, for treating non-human objects as neutral phenomena, defined in self-referential social terms, which are not themselves "allowed to make a difference to our thinking about them" (Latour, 1999, p. 117)..$^{5}$

Each of the perspectives I have described-the phenomena-focused and the socioculturally-oriented knower-focused-therefore tends to give the impression that it alone is telling 'the whole story' and that the other perspectives, if acknowledged at all, are of marginal or background importance. There is little productive intercourse between the streams; no one, it seems, wants to engage with both sorts of complexity. And since interdisciplinary and interprofessional researchers and educators typically draw upon one or other of these perspectives, their activities tend to embody the same sort of conceptual polarization.

On a practical level, this polarization of perspectives leads to frustration on the part of educators, researchers and practitioners working in interdisciplinary and

\footnotetext{
${ }_{5}^{5}$ The scientific knowledge sociologist Turnbull $(2009 ; 1997)$ takes great care to ground all knowledge, including modern western scientific knowledge, in relation to particular people, practices and places. All such traditions, whether among prehistoric Polynesian navigators or modern cartographers, create "knowledge spaces" and his foremost concern is finding ways for diverse knowledge spaces to co-exist (Turnbull, 1997, pp. 552-553). In his rich accounts of these "spaces", Turnbull implies that many sorts of knowledge-especially indigenous ones-are well adapted to local physical and natural surroundings. As with others who emphasize socio-cultural dynamics, however, the world itself seems to lack any structure or integrity of its own; it appears mostly as a backdrop amenable to multiple, diverse sorts of human knowing (Turnbull, 2009;
} 1997). 
interprofessional contexts. I have met many natural scientists who attend diligently to the phenomena they study and 'get their backs up' when told that knowledge is just a social construction. Similarly, those with a background in the social sciences get understandably frustrated when told that knowledge is simply a reflection of the way the world is'. ${ }^{6}$

Not surprisingly, given how I have framed these issues, I think that a robust and generative understanding of interdisciplinarity (and interprofessionalism) should acknowledge both the phenomena-focused perspective and the socio-culturallyoriented, knower-focused perspective: That they exist, that they are different, and that each offers valuable insights. Furthermore, interdisciplinary theorists and educators need to start thinking about integrating these perspectives-that is, about the relationship between these perspectives and what it means for conceptions of disciplinary and interdisciplinary (as well as professional and interprofessional) knowledge.

\section{Integrating complexities of both knowers and phenomena}

The literature on interdisciplinary and interprofessional research and education has developed a great deal in past decade. Interdisciplinary thinkers such as Newell (2001a), Klein (1996), Augsburg (2006) and Repko (2008) have offered both sophisticated theorizing and pragmatic step-by-step guidelines for integrating-without conflating or reducing-diverse disciplinary insights. The interprofessional literature tends to be more closely linked to the pragmatic concerns of, for example, healthcare and policy professionals. It too, though, has produced a great deal of useful research on interprofessional teamwork, stressing the importance of conditions such as competence in one's specialization, mutual respect and trust, openness to other ways of thinking, and awareness of the role of language and power (D'Amour \& Onadasan, 2005; Hall, 2005). Those in the complexity \& education community who wish to study or teach across disciplines or professions could benefit greatly from exposure to this literature.

As we have seen, however, this literature is polarized into two perspectives: One that focuses on the complexities of phenomena and one that attends to socio-cultural dynamics among disciplinary knowers. Interdisciplinary and interprofessional scholars and educators thus require new and different ways of thinking about knowledge, ways that acknowledge and integrate the two perspectives and avoid the extremes of both naïve realism and naïve social constructivist relativism-views that, as Phelps and Davis (2005) write, refuse to "collapse phenomena with knowledge of phenomena. These are inextricably entangled, but not coterminous" (p.3). Where might we find such views?

\footnotetext{
${ }^{6}$ Indeed, this sort of misunderstanding can even be seen within the walls of education faculties. Educational psychologists may pursue methodologically sophisticated examinations of narrow aspects of the learning process without reflexively analyzing political and power-related issues. And critical educators well-versed in such reflexive analyses may argue that biological characteristics identified by scientists are nothing more than social constructions.
} 
I believe that these views can be derived from thinking already taking place with the complexity \& education community and by a number of theorists who have inspired this community: Dewey, Maturana and Varela, and Merleau-Ponty. Thinking within this community, not surprisingly, focuses on individual learners, schools and classrooms. However, much of it can be extended to the phenomena and socio-cultural processes of concern to interdisciplinary researchers and educators in post-secondary institutions. ${ }^{7}$

In what follows, I will briefly describe several epistemological insights articulated within the complexity \& education community and illustrate how they can provide a more productive and integrated framework for interdisciplinarity and interprofessionalism. The first insight concerns the complexity of knowers; the second involves the relationship between knowers and phenomena; and the third deals with the relationality and temporality of all knowing.

\section{Complex knowers, not just complex phenomena}

As we have seen, insights from complexity science have had a significant effect on how interdisciplinary and interprofessional researchers and educators approach phenomena; ecological, multilevel-often explicitly complexivist-models are becoming more prominent in a variety of areas. Complexivist, multileveled approaches have had less of an impact, however, on interdisciplinarians focusing on the 'knowers' doing the studying. They focus almost entirely on collective, sociological processes-rather than, say, individual or evolutionary perspectives on human knowing. The first insight that the complexity \& education community can offer, then, is a way to expand knower-side research and education beyond such (admittedly very important) sociological approaches.

Recall from above that complexity science is concerned with living systems at multiple levels-from cells and organs, to persons, social groups, societies and ecosystems. From a complexity perspective, each of these adaptive, self-organizing systems can be seen as cognitive, or as a learner, and each has its own emergent sort of behaviours and relevant disciplinary discourses-for instance, constructivist psychology at the level of the personal understanding or anthropology at the level of cultural evolution (Davis \& Sumara, 2006). The socio-cultural dynamics described by knoweroriented interdisciplinary theorists-the competition, cooperation, power games and other tensions both within and between collective disciplinary and interdisciplinary 'knowers' — can thus be seen as particular instances of the emergent, self-organizing and adaptive behaviour of complex systems (Davis, Sumara \& Luce-Kapler, 2008; McMurtry, 2006). ${ }^{8}$

\footnotetext{
${ }^{7}$ Indeed, a paper I wrote- based on ideas similar to those developed more fully in this articlewas recently published in the 2009 volume of Issues in Integrative Studies, the journal of the Association for Integrative Studies.

${ }^{8}$ It is not surprising that educators have applied complexity in a more reflexive way to matters of knowing than those in other disciplines I have discussed. After all, the phenomena they study are learning and knowing. This is obviously not so much the case for those in, say, healthcare, criminology, or economics.
} 
Framing socio-cultural perspectives within complexivist terms will no doubt incense some interdisciplinary theorists with a critical or poststructuralist bent. However, I believe that it offers an important benefit: Bringing socio-cultural discourses into conversation with (non-mechanistic) physical, biological and evolutionary perspectives on learning and knowing that are typically ignored by socio-cultural theorists. These include not only constructivist and evolutionary perspectives, but also Lakoff and Johnson's (1999) view that even our most abstract concepts are ultimately rooted in and dependent upon our physical embodiment, as well as Maturana and Varela's (1992) enactivist view of the biological roots of human understanding (sometimes called the 'Santiago theory of cognition').

For interdisciplinary and interprofessional researchers and educators, such framing offers an opportunity to broaden their analyses of 'knower-side' issues. For example, it provides as way to think about how many individuals' understandings may be influenced by more than the disciplines or professions in which they are socialized. Such expanded framing also allows one to consider how the historical development of disciplinary bodies and knowledge categories may be a function not only of sociocultural tensions but of human beings' evolution within specific ecosystems. These factors, which are typically absent from most socio-cultural analyses, can be seen as shaping possibilities for human knowing too. The recent emergence of environmental awareness and hybrid disciplines like environmental ethics or ecological economics (from previously separate disciplines) is difficult to explain solely by reference to sociocultural issues. Surely those studying such developments should acknowledge the relevance-even when focusing on the 'knowers-side' - of issues like human embodiment within the world, cultural and personal experience of the health effects of pollution, and alienation from the more-than-human world in contemporary urbanized societies (Abram, 1996).

An implication of the preceding argument is that disciplinary and interdisciplinary knowledge can be characterized in terms of one kind of complex system (in this case, individual and collective human knowers) interacting with other systems that are often themselves complex (for example, bodily systems and organs in medicine; ecosystems in ecology; or students and schools in education) ${ }^{9}$. This relational depiction of knowers and phenomena has important epistemological consequences, which are explored in the next two subsections.

\section{The relationship between knowers and phenomena}

Traditionally in western cultures, the relationship between knowers and phenomena has been characterized in terms of representation or correspondence. That is, knowers' beliefs are thought to constitute knowledge if they accurately represent, or correspond with, some aspect of 'objective reality.' This view of knowledge underlies much debate

\footnotetext{
${ }^{9}$ Of course, the phenomena studied by disciplinary and interdisciplinary knowers may also include simple systems, like the buildings constructed by civil engineers, or complicated systems, such as the gases studied by chemists.
} 
within the interdisciplinary and interprofessional community, with thinkers problematizing either one side or the other of this subjective knower/objective reality dichotomy. Those who focus on socio-cultural issues argue that objectivity is impossible because knowledge is inherently subjective and inseparable from considerations of history, language, power and so on (see for example, Klein, 2001). On the other hand, those who focus on phenomena tend to stress that knowledge, especially scientific, cannot be entirely subjective; it must correspond in some way to reality, otherwise it would not work (see, for example, Newell, 2001b). Despite this apparent impasse, the underlying assumption that discussions of knowledge need to be framed in representational terms has not been explicitly or systematically questioned within the interdisciplinary and interprofessional communities..$^{10}$

Another contribution that the complexity \& education community can make to interdisciplinary and interprofessional theory is, therefore, to offer a persuasive alternative to representationism. This alternative builds on constructivist and pragmatist thought. It characterizes knowledge in terms of coherence, viability or fit with local needs and constraints, rather than correspondence with an 'objective' reality (see, for example, Proulx, 2006; Biesta \& Burbules, 2003; Davis, Sumara \& Luce-Kapler, 2008). The concept of coherence in this case refers not only to external coherence (the viable relationships among a knower and various phenomena in its environment) but also internal coherence (the relationships within a knower's internal beliefs or physical structures).

This conception of knowing provides a more fertile ground for interdisciplinary inquiry than representationism for several reasons. First, representationism implies that there is ultimately only one 'correct' way to view the world. Coherence or viabilityoriented views of knowledge, on the other hand, allow for multiple ways of knowing, each appropriate to different contexts or aspects of the world. Obviously, this latter view of knowledge provides validation for the use of interdisciplinary approaches. Second, the concept of viability or fit between a knower and phenomena compels one to consider both 1) the relationships among interdisciplinary knowers and the various, often incommensurable, phenomena with which they interact (external coherence), and 2) the complexity (socio-cultural and otherwise) of the disciplinary and interdisciplinary knowers doing the studying (internal coherence).

When examining the phenomenon of acid rain from an interdisciplinary perspective, for example, a researcher or educator would need to consider not only 1)

\footnotetext{
${ }^{10}$ Representationism has been thoroughly and convincingly critiqued from a number of perspectives. Structuralist and poststructuralist thinkers have argued that we cannot access the world - as it is, in itself-apart from our own personal history, language and cultural context (Belsey, 2002). A more biologically-oriented critique offered by the enactivists Varela, Thompson \& Rosche's (1991). By asserting that the mind contains representations of an external world, they write, representationists concede that cognition is externally determined-something that fundamentally contradicts the self-organizing nature of living organisms (Varela et al., 1991). What is surprising, given these critiques, is that no alternative to it has taken widespread root within many academic circles
} 
the complex interactions of chemicals, biological processes, hydrological cycles, global economic trends, and political developments, but also 2) the complex socio-cultural dynamics occurring within and among the various disciplinary groups involved, such as chemists, biologists, hydrogeologists and economists. Similarly, interprofessional health teams caring for diabetic patients should be aware of both 1) relevant physiological, nutritional, personal and sociological subjects, and 2) issues related to team communication, respect for different specialties, professional status and so on.

\section{Knowledge is relational and dynamic}

A final contribution that the complexity \& education community can make to interdisciplinary and interprofessional inquiry is a recognition that knowledge is not ultimately isolatable in either knowers or the world's phenomena; rather, is enacted in dynamic relationships (Davis \& Sumara, 2006). This relational view of knowledge features prominently in the thinking of several influential figures who have inspired this community. One such figure is John Dewey. His theory of transactional realism takes as its starting point not traditional Western philosophy's assumed separation of mind and world, but rather the on-going lived experience of human organisms in their environments. Knowledge, from this perspective, is never simply a human construction; nor is it an objective representation of the 'real' world. Instead, it is located in the transactions between the knower and the world (Biesta \& Burbules, 2003).

It also evident in the phenomenology of Merleau-Ponty (1962), which depicts perception not as passive 'mental' observation, but rather as active and embodied engagement with the rest of the world. Meaning, he asserts, emerges through these mutually-affective interactions; it cannot be isolated in either the knower or the world. One further example this relational perspective is Maturana and Varela's (1992) ecologically-rooted theory of enactivism. These theorists understand cognition in terms of the on-going processes of mutual adaptation among knowers and their environments. Knowledge is not something 'stored' within a knower; rather, it is enacted in effective interactions between knowers and their worlds. Indeed, from these perspectives, knowledge might be more accurately termed knowing, since it is embodied in actions and relationships and is not considered a static or isolatable thing.

Furthermore, these knowing relationships should be seen as dynamic and evolving, rather than as any sort of final or settled truths. Both knowers and the phenomena they study are changing; indeed, they are co-evolving, as worldly phenomena help shape knowers' understandings and knowers' understandings and actions contribute to the shaping of the world (Davis, 2004). Osberg, Biesta and Cilliers (2008) offer a helpful précis of this relational and provisional view of knowing:

$[\mathrm{M}]$ odels and theories that reduce the world to a system of rules or laws cannot be understood as pure representations of a universe that exists independently, but should rather be understood as valuable but provisional and temporary tools by means of which we constantly re-negotiate our understanding of and being in the world. (p. 218)

There is no final truth of the matter, only increasingly diverse ways of interacting in a world that is becoming increasingly complex. (p. 223) 
This epistemological insight concerning the relationality and temporality of knowing is, I believe, especially important for interdisciplinary and interprofessional researchers and educators. It implies that there is nothing eternal or fixed about disciplinary boundaries. As both knowers and phenomena change and affect one another over time, we can expect disciplinary knowing to continually shift, merge and differentiate-something that actually corresponds very well with Klein's (1986) description of the messy history of disciplines and interdisciplinarity.

This insight also draws attention to the fact that interdisciplinary and interprofessional knowing is in the world, participating in its unfolding. As we attempt to understand and interact with complex phenomena like healthcare, crime or learning, we inevitably contribute to the world's complexity.

\section{Conclusion}

The goal of this paper has been to open a productive conversation between the complexity \& education community and the emerging fields of interdisciplinarity and interprofessionalism. Many of the ideas it contains-concerning complexity science, learning and knowers, for example-are not new to Complicity. However, the elaboration of these ideas within the context of interdisciplinary and interprofessional inquiry does provide something new, especially for educators wishing to pursue research or teaching across disciplinary or professional boundaries.

Specifically, I have described two very different streams of thinking in the literature on interdisciplinary education and research: One that focuses on the socio-cultural dynamics among disciplinary knowers and one that emphasizes the complexity of the phenomena studied by these disciplinary knowers. Further, I have shown how ideas developed within the complexity \& education community can be used to integrate these previously separate streams of thought.

The distinction I have made between knowers and phenomena may be largely an analytic one. Something that is a knower from one perspective may be a phenomenon from another (for example, a person may be a psychologist and/or the focus of psychological study). And knowledge-or more accurately, knowing-may (as was argued above) be enacted in relationships and thus spread across distinctions between knowers or phenomena. However, like most distinctions, the one between knowers and phenomena does serve a concrete purpose: Helping interdisciplinary and interprofessional researchers and educators better understand their own activities.

\section{References}

AIS Connected Publications. 2010. Association for Integrative Studies. Retrieved April 27, 2010, from http://www.units.muohio.edu/aisorg/PUBS/aisbib.html

Abbott, A. 1988. The system of professions: An essay on the division of expert labor. Chicago: University of Chicago Press.

Abram, D. 1996 The spell of the sensuous: Perception and language in a more-than-human world. New York: Pantheon. 
Augsburg, T. 2005. Becoming interdisciplinary: An introduction to interdisciplinary studies. Dubuque, IA: Kendall/Hunt.

Barak, G. 1998. Integrating criminologies. Boston: Allyn \& Bacon.

Beattie, A. 1995. Troubled times: war and peace among the health tribes. In Interprofessional relations in health care, edited by L. Mackay, K. Soothill \& C. Webb, 11-26. London: Edward Arnold.

Bell, I., Caspi, O., Schwartz, G., Grant, K., Gaudet, T., Rychener, D., Maizes, V. \& Weil, A. 2002. Integrative medicine and systematic outcomes research: Issues in the emergence of a new model for primary health care. Archives of Internal Medicine 162, 133-140.

Belsey, C. 2002. Postructuralism: A very short introduction. Oxford: Oxford.

Biesta, G. \& Burbules, N. 2003. Pragmatism and educational research. Lanham, MD: Rowman \& Littlefield Publishers.

Bloor, D. (1999) Anti-Latour. Studies in History and Philosophy of Science, 30(1), 81-112.

Capra, F. 2002. Hidden connections: Integrating the biological, cognitive, and social dimensions of life into a science of sustainability. New York: Doubleday.

Cultural historical activity theory. 2004. University of Helsinki Centre for Activity Theory and Developmental Work Research. Retrieved on July 21, 2005 from http://www.edu.helsinki.fi/activity/

D'Amour, D. and Onadasan, I. 2005. Interprofessionality as the field of interprofessional practice and interprofessional education: An emerging concept. Journal of Interprofessional Care 19(S1), 8-20.

Davis, B. 2005. Inventions of teaching: A genealogy. Marwah, NJ: Lawrence Erlbaum.

Davis, B., \& Sumara, D. 2006. Complexity and education. Marwah, NJ: Lawrence Erlbaum.

Davis, B., Sumara, D., \& Luce-Kapler, R. 2008. Engaging minds: Changing teaching in complex times (2 ${ }^{\text {nd }}$ $E d)$. New York: Routledge.

Doll, W. 1993. A post-modern perspective on curriculum. New York: Teachers College Press.

Hall, P. 2005. Interprofessional teamwork: Professional cultures as barriers. Journal of Interprofessional Care 19(S1), 188-196.

Health Canada. n.d.. Primary health care transition fund. Retrieved on August 5, 2005 from http:/www.hc-sc.gc.ca/hcs-sss/prim/phctf-fassp/index_e.html

Henry, S. 2009. School violence beyond columbine: A complex problem in need of an interdisciplinary analysis. American Behavioral Scientist 52(9), 1246-1265.

Hiatt, R. \& Breen, N. (2008). The social determinants of cancer: A challenge for transdisciplinary science. American Journal of Preventive Medicine, 35(S2), 141-150.

Klein, J.T. 2004. Interdisciplinarity and complexity: An evolving relationship. Emergence: Complexity and Organization 6(1-2), 2-10.

Klein, J.T. 2001. Interdisciplinarity and the prospect of complexity: The tests of a theory. Issues in Integrative Studies 19, 1-25.

Klein, J.T. 1996. Crossing boundaries: Knowledge, disciplinarities, and interdisciplinarities. Charlottesville, VA: University Press of Virginia

Klein, J.T. 1986. The dialectic and rhetoric of disciplinarity and interdisciplinarity. In Interdisciplinary analysis and research: Theory and practice of problem-focused research and development, edited by D. Chubin, A. Porter, F. Rossinei, \& T. Connolly, 7-130. Mt. Airy, MD: Lomond.

Klein, J.T. \& Newell, W.H. 1998. Advancing interdisciplinary studies. In Interdisciplinarity: Essays from the literature, edited by W. Newell, 3-22. New York: College Board.

Lakoff, G. \& Johnson, M. 1999. Philosophy in the flesh: The embodied mind and its challenge to Western thought. New York: Basic Books.

Latour, B. 1999. For David Bloor... and beyond: A reply to David Bloor's 'Anti-Latour'. Studies in History and Philosophy of Science, 30(1), 113-129.

Lave, J. \& Wenger, E. 1991. Situated learning: Legitimate peripheral participation. Cambridge: University of Cambridge Press. 
Leischow, S., Best, A., Trochim, W., Clark, P., Gallagher, R., Marcus, S. \& Matthews, E. 2008. Systems thinking to improve the public's health. American Journal of Preventive Medicine 35(S2), 196-203.

Mabry, P., Olster, D., Morgan, G. \& Abrams, D. 2008. Interdisciplinary and systems science to improve population health: A view from the NIH office of behavioral and social sciences research. American Journal of Preventive Medicine 35(S2), 211-224.

Maturana, H.R., \& Varela, F.J. 1992. The tree of knowledge: The biological roots of human understanding (rev. edition). Boston: Shambhala.

McMurtry, A. 2006. Linking complexity theory with cultural historical activity theory. International Journal of Research and Method in Education 29(2), 209-219.

Merleau-Ponty, M. 1962. Phenomenology of perception. London, UK: Routledge and Kegan Paul.

Osberg, D., Biesta, G. \& Cilliers, P. 2008. From representation to emergence: Complexity's challenge to the epistemology of schooling. Educational Philosophy and Theory 40(1): 213-227.

Newell, W.H. 2001a. A theory of interdisciplinary studies. Issues in Integrative Studies 19, 1-25.

Newell, W.H. 2001b. A reply to the respondents to "A theory of interdisciplinary studies". (2001). Issues in Integrative Studies 19, 137-148.

Pea, R. 1993. Practices of distributed intelligence and designs for education. In Distributed cognitions, edited by G. Salomon, 47-87. New York: Cambridge University Press.

Phelps, R. \& Davis, B. 2005. Exploring the common spaces of education and complexity: Transphenomenality, transdisciplinarity, and interdiscursivity. Complicity: An International Journal of Complexity and Education 2(1), 1-4.

Proulx, J. 2006. Constructivism: A re-equilibration and clarification of the concepts, and some potential implications for teaching and pedagogy. Radical Pedagogy 8(1), http://radicalpedagogy.icaap.org/content/issue8_1/proulx.html

Repko, A. 2008. Interdisciplinary research: Process and theory. Thousand Oaks, CA: Sage.

Robinson, M.B. \& Beaver, K.M. 2009. Why crime? An interdisciplinary approach to explaining criminal behavior. Durham, NC: Carolina Academic Press.

Stokols, D., Hall, K., Taylor, B \& Moser, R. 2008. The science of team science: Overview and of the field and introduction to the supplement. American Journal of Preventive Medicine 35(S2), 77-89.

Turnbull, D. (2009) Working with Incommensurable Knowledge Traditions: Assemblage, Diversity, Emergent Knowledge, Narrativity, Performativity, Mobility and Synergy. Retrieved April 24, 2010, from http://houghtmesh.net/publish/279.php

Turnbull, D. 1997. Reframing science and other local traditions. Futures, 29(6), 551-562.

Varela, F., Thompson, E. \& Rosch, E. 1991. The embodied mind: Cognitive science and human behaviour. Cambridge, MA: MIT Press.

\section{About the Author}

Angus McMurtry (angus.mcmurtry@uottawa.ca) is an assistant professor in the Faculty of Education at the University of Ottawa. He has degrees in philosophy, law and education, as well as entrepreneurial experience in the software field. His PhD dealt with the education of interprofessional healthcare teams. Current research interests span the following topics: collective learning, occupational knowledge, interdisciplinary theory, interprofessional teamwork, collaborative action research, and complexity science. See www.education.uottawa.ca/en/faculty/professors?p=amcmurtry

(C) Copyright 2009. The author, ANGUS MCMURTRY, assigns to the University of Alberta and other educational and non-profit institutions a non-exclusive license to use this document for personal use and in courses of instruction provided that the article is used in full and this copyright statement is reproduced. The authors also grant a non-exclusive license to the University of Alberta to publish this document in full on the World Wide Web, and for the document to be published on mirrors on the World Wide Web. Any other usage is prohibited without the express permission of the authors. 